\title{
Roles of Infected Seed Tubers and Soilborne Inoculum on Verticillium Wilt of 'Russet Burbank' Potato
}

\author{
Jeremiah K. S. Dung and Dennis A. Johnson, Department of Plant Pathology, Washington State University, Pullman 99164
}

\begin{abstract}
Dung, J. K. S., and Johnson, D. A. 2012. Roles of infected seed tubers and soilborne inoculum on Verticillium wilt of 'Russet Burbank' potato. Plant Dis. 96:379-383.

Verticillium dahliae, causal agent of Verticillium wilt of potato, persists in soil as microsclerotia and can be found in infected tubers used for seed. The effects of naturally infected tubers and soilborne inoculum on Verticillium wilt symptoms were compared in the greenhouse. Infected and noninfected tubers were grown in infested and noninfested potting soil. Chlorosis and necrosis were measured and converted to area under senescence progress curves (AUSPC). Aboveground stems and progeny tubers were assayed for $V$. dahliae. Plants from infested soils exhibited significantly greater AUSPC than plants from noninfested soil. Plants grown from infected and noninfected tubers had

similar AUSPC and interactions between infected tubers and infested soil were not observed. The pathogen was isolated from the vascular system of $94 \%$ of plants grown in infested soils and $8 \%$ of plants grown from infected tubers in noninfested soil. Plants grown in infested soil contained microsclerotia on $46 \%$ of stems while plants grown from infected tubers in noninfested soils exhibited microsclerotia on $<1 \%$ of stems. Infected progeny tubers were only recovered from plants grown in infested soil. Seed tuber infection did not contribute to premature senescence or potential inoculum production, indicating that management efforts should focus on reducing soilborne inoculum.
\end{abstract}

Verticillium wilt of potato (Solanum tuberosum L.) is a disease of major economic importance to potato-growing regions around the world. The primary causal agent of Verticillium wilt of potato is Verticillium dahliae Kleb., a soilborne fungal pathogen with an extensive host range and widespread distribution (44). Symptoms of Verticillium wilt of potato include unilateral wilting, chlorosis, and necrosis which results in premature senescence of the plant. Symptoms typically occur unilaterally and progress acropetally. Senescent stems often remain upright and contain microsclerotia, the primary resting structures and overwintering inoculum of $V$. dahliae. Reports on the effects of Verticillium wilt on yield are variable, ranging from $12 \%$ (27) to $30 \%$ or more (6), and reductions in potato yields are not necessarily correlated with aboveground symptoms $(34,45)$. Yield reductions and symptom expression may be influenced by cultural and environmental conditions $(7,40)$ and can be more pronounced during periods of heat stress and high rates of evapotranspiration $(17,20,37,45)$.

Verticillium wilt is a monocyclic and polyetic disease, and primary inoculum consists of microsclerotia which form during plant senescence and can persist in soil for long periods of time $(22,30,46)$. Reported disease thresholds for Verticillium wilt in potato range between 5 and $30 \mathrm{CFU} / \mathrm{cm}^{3}$ of soil for $V$. dahliae alone and from 2 to $13 \mathrm{CFU} / \mathrm{cm}^{3}$ soil when $P$. penetrans is present (40). Microsclerotia are stimulated to germinate in response to host root exudates (32), and hyphae colonize the cortex and invade the xylem, where they are systemically translocated through the host vascular system (19). A short saprophytic phase occurs at host senescence, during which $V$. dahliae produces microsclerotia in colonized tissue and completes the disease cycle. Microsclerotia production in potato is most abundant on aerial stems (33), and

Corresponding author: J. K. S. Dung, E-mail: dungj@wsu.edu

PPNS Number 0516, Department of Plant Pathology, College of Agricultural, Human, and Natural Resource Sciences Agricultural Research Center, Project Number WNP00678, Washington State University, Pullman 991646430.

Accepted for publication 7 October 2011.

http://dx.doi.org/10.1094/PDIS-07-11-0583

(C) 2012 The American Phytopathological Society colonized host debris can increase inoculum levels if incorporated into the soil. Although no sexual stage is known to occur, genetic diversity does exist in the form of several distinct vegetative compatibility groups (VCGs). Isolates from potato plants and potato fields in Oregon and Washington are predominantly VCG 4A and VCG 4B, and VCG 4A isolates have been found to be more aggressive on potato than other VCGs $(25,38,39)$.

In addition to soilborne inoculum, intratuber inoculum of $V$. dahliae can be found in the vascular system of certified seed tubers. Surveys in 1968 and 1969 detected V. albo-atrum and V. dahliae in $39 \%$ of 244 certified seed lots, with the incidence of Verticillium spp. within lots ranging between 1 and $2 \%$ and rarely exceeding 5\% (16). A study conducted between 1995 and 1998 detected low levels of $V$. dahliae ( $<5 \%$ incidence) in 20 to $30 \%$ of seed lots imported from northern Europe to Israel. However, up to $16 \%$ of seed lots contained higher levels ( $>5 \%$ incidence) of infected tubers (48). Surveys of 224 seed lots intended for North American production fields in 1995 and 1996 detected $V$. dahliae in $29 \%$ of seed lots. Although the mean incidence of $V$. dahliae infection within lots was only $4 \%$, approximately $64 \%$ of isolates were VCG 4A, 33\% were VCG 4B, and 3\% were VCG 4AB (39). The detection of $V$. dahliae in certified potato seed lots and prevalence of the more aggressive VCG 4A in both seed tubers and major potato-producing areas (38) may have important implications in commercial seed and production systems as well as the epidemiology and distribution of the disease.

Despite the prevalence of $V$. dahliae in certified commercial seed lots, the contributions of infected seed tubers to the development and epidemiology of Verticillium wilt are not fully understood. Robinson et al. (42) determined that vascular infection of seed tubers by $V$. albo-atrum did not cause symptomatic plants in several potato cultivars. A 1979 field study found no effect of intratuber infection by $V$. dahliae on plant growth, disease symptoms, yield, or quality in 'Norgold Russet' potato (23). However, wilt severity resulting from intratuber infection can vary among cultivars (42) and the effects of vascular infection by $V$. dahliae in seed tubers has not been evaluated in 'Russet Burbank' potato, a major long-season cultivar (35) which is moderately susceptible to Verticillium wilt (51). In addition, knowledge regarding the potential role of infected seed tubers in the production of primary inoculum will aid in the management of Verticillium wilt of potato. The objectives of this study were to (i) determine the relative roles of 
naturally infected seed tubers and soilborne inoculum in the development of Verticillium wilt symptoms in Russet Burbank potato and (ii) quantify the incidence of vascular host colonization, total microsclerotia production on senescent stems, and the incidence of infected progeny tubers to assess the contributions of seed tuber infection to soilborne inoculum.

\section{Materials and Methods}

Soil infestation. Soil inoculum consisted of rye kernels colonized with $V$. dahliae isolate 653 and was prepared as described by Atibalentja and Eastburn (3). Isolate 653 was isolated from potato and previously identified as VCG 4A and pathogenic on potato (12). Kernels were ground in an IKA MF 10.1 mill (IKA Works, Inc., Wilmington, NC) and the ground inoculum was quantified via serial dilution. Infested soil treatments were prepared by adding ground inoculum to 6.6-liter pots (J. M. McConkey \& Co., Inc., Sumner, WA) containing 5.0 liters of Sunshine L2 greenhouse potting mix (Sun Gro Horticulture, British Columbia, Canada) and approximately $32 \mathrm{~g}$ of granular 16-16-16 N-P-K fertilizer (Agriliance Agronomy Co., St. Paul, MN) to achieve a concentration of approximately $10 \mathrm{CFU} / \mathrm{cm}^{3}$. Ground noninfested rye was added to the noninfested soil treatments.

Selection of naturally infected tubers. Naturally infected Russet Burbank seed potato tubers grown in Montana and Idaho and intended for commercial production fields were collected from certified seed lots. Random samples of 35 tubers were assayed from 17 seed lots in 2007 and 10 seed lots in 2008. Seed tubers were thoroughly scrubbed with a sponge under running distilled water and allowed to air dry. A 15-mm round disk which included vascular tissue was cut from the stem end of the tuber and plated onto NP-10 medium (5). Plates were incubated at $23^{\circ} \mathrm{C}$ and visually inspected for $V$. dahliae colonies after 14 days.

Ten infected seed tubers were selected for use as naturally infected seed piece treatments from four seed lots in 2007 and from five seed lots in 2008. Noninfected seed piece treatments consisted of 10 seed tubers which were selected based on negative results in the plate assays. Care was taken to choose seed tubers which were free of other fungal pathogens (e.g., Colletotrichum coccodes and Fusarium spp.). Each infected tuber was paired with a noninfected seed tuber derived from the same seed lot and of similar size. Because the 20 seed tubers selected from the assays were too large to plant as whole tubers, each seed tuber was cut crosswise and then lengthwise into four equalsized pieces (approximately $60 \mathrm{~g}$ ) with at least two eyes each. Experimental units consisted of two plants (subsamples), each grown from an apical and basal seed piece cut from the same seed tuber. Seed pieces were planted and arranged in the greenhouse as a randomized complete block design with 10 replicates. All eight plants within a block were grown from tubers derived from the same seed lot. The trial was performed once in 2007 and repeated in 2008.

Disease evaluation. Plant senescence was assessed at 65 days after planting and approximately weekly thereafter until crop senescence was completed (142 days for the first trial in 2007 and 133 days for the second trial in 2008). Plants were evaluated for the percentage of chlorosis and necrosis over the entire plant and values were combined to obtain an overall senescence value. Senescence values over time were converted to area under senescence progress curves (AUSPC) using the equation $\Sigma_{i}^{n-1}\left[\left(Y_{i}+\right.\right.$ $\left.\left.Y_{i+1}\right) / 2\right]\left(t_{i+1}-t_{i}\right)$, where $Y_{i}=$ cumulative necrosis at the $i$ th observation, $t_{i}=$ time (days postinoculation) at the $i$ th observation, and $n=$ number of observations. AUSPC values of noninfected tubers planted in noninfested soil were considered to be representative of natural senescence. AUSPC values were also converted to senescence ratios using the following formula: AUSPC $\operatorname{ratio}_{\mathrm{n}(\mathrm{x})}=$ $\mathrm{AUSPC}_{\mathrm{n}(\mathrm{x})} /$ mean AUSPC $_{\text {control }}$, where $\mathrm{AUSPC}_{\mathrm{n}(\mathrm{x})}=\mathrm{AUSPC}$ for of a particular treatment $(x)$, and $\mathrm{AUSPC}_{\text {control }}=$ the mean AUSPC of plants grown from noninfected tubers in noninfested soil. A senescence ratio $>1$ indicates premature senescence compared with noninoculated control plants.
Stem sampling and progeny tuber assays. A single aboveground stem from each plant was destructively sampled to assay aboveground vascular colonization by $V$. dahliae. Stems were sampled when plants appeared to be within a week of senescence (after the plant was at least $80 \%$ necrotic but before desiccation of the stem). A cross-section, $1 \mathrm{~cm}$ in length, was taken $30 \mathrm{~cm}$ above the soil line and plated onto NP-10 medium. Plates were incubated for 1 week and data were recorded as either a 0 ( $V$. dahliae absent) or 1 ( $V$. dahliae present). The remaining stems in the containers were left to dry for 3 weeks and visually assayed for $V$. dahliae microsclerotia using a dissecting microscope. Microsclerotia colonization was recorded as the percentage of stem colonization in relation to total stem length and results from all stems were combined to calculate the mean microsclerotia colonization per plant. Accuracy of the visual assay was confirmed by taking samples 1 to $2 \mathrm{~cm}$ above and below the transition between colonized and noncolonized tissue of 24 randomly selected stems and plating onto NP-10. In total, seven randomly selected progeny tubers from each plant were assayed for $V$. dahliae infection as described above.

Data analysis. Data for each experimental unit consisted of mean values from two subsamples (plants). Analysis of variance (ANOVA) was performed using PROC MIXED in SAS (version 9.1; SAS Institute, Cary, NC). Data from both trials were analyzed as a two-way factorial randomized complete block design, with treatments consisting of tuber infection and soil infestation. Mean comparisons were performed using Tukey's honest significant difference (49).

Characterization of isolates from infected tubers. Attempts were made to collect isolates of $V$. dahliae from the infected tubers used in this study for VCG characterization. Single-spore cultures were collected directly from seed tuber assay plates when possible and maintained on $1 \%$ potato dextrose agar (potato dextrose agar at $10 \mathrm{~g} /$ liter and agar at $15 \mathrm{~g} / \mathrm{liter}$ ). Isolates were also stored on colonized filter paper disks at $-20^{\circ} \mathrm{C}$. Isolates were assigned to VCG according to Joaquim and Rowe (24), with a few modifications (13).

Isolates collected from infected seed tubers used in this study were also tested for pathogenicity on potato. Rooted plants, approximately $15 \mathrm{~cm}$ tall, were separated from certified Russet Burbank seed tubers sprouted in trays containing LC1 potting mix. Single-stem plants were transplanted into $10-\mathrm{cm}$-wide square pots filled with $500 \mathrm{~cm}^{3}$ of potting mix and grown for 2 weeks. Conidial suspensions of the $V$. dahliae isolates from infected seed tubers were prepared and quantified as previously described (13). In addition, isolates 653 (VCG 4A control) and 239 (VCG 4B control), both obtained from potato, and a water control were also included. Plants were inoculated by drenching the soil with a conidial suspension at a final concentration of $10^{5} \mathrm{CFU} / \mathrm{cm}^{3}$ of potting medium. Each treatment combination was replicated four times and plants were arranged in the greenhouse using a randomized complete block design. Plants were evaluated for the percentage of chlorosis and necrosis at 4, 6, and 7 weeks post inoculation and values were converted to AUSPC. Data were analyzed using PROC MIXED in SAS and pairwise comparisons of treatments with isolate 653 were performed using Dunnett's procedure (14).

\section{Results}

Disease evaluation. Mean AUSPC values and senescence ratios were significantly $(P<0.0001)$ higher in potato plants grown in infested soil than in plants grown in noninfested soil in both trials (Table 1). Plants grown from infected and noninfected seed tubers in noninfested soil were not significantly different with regards to AUSPC values and senescence ratios in either trial $(P \geq 0.3023)$. Significant interactions between infected seed piece and infested soil treatments were not detected $(P \geq 0.1192)$ in either 2007 or 2008. A number of plants were lost due to seed piece decay during the 2008 trial; however, ANOVA results from the 2008 trial were consistent with those from the 2007 trial.

Stem sampling and progeny tuber assays. Vascular colonization of aboveground stems by $V$. dahliae significantly $(P<0.05)$ increased in plants grown in infested soil compared with infected 
and noninfected tubers grown in noninfested soil. Mean microsclerotia colonization of aboveground stems and the number of $V$. dahliae-infected progeny tubers were significantly $(P<0.0001)$ greater in plants grown in infested soil compared with plants grown from infected seed pieces in noninfested soil. Vascular infection of seed tubers by $V$. dahliae did not significantly contribute to vascular colonization of aboveground stems $(P>0.05)$, microsclerotia production in senescent stems $(P \geq 0.3668)$, or progeny tuber infection $(P \geq 0.5642)$ compared with noninfected seed tubers (Table 1), and interactions were not observed $(P \geq 0.2973)$. Plants grown from infected tubers exhibited microsclerotia on 0 to $7 \%$ of stems, while plants grown in infested soil contained microsclerotia on 0 to $91 \%$ of stems. The pathogen was not detected in or on any stems or progeny tubers from the noninfected and noninfested control treatment.

Characterization of isolates from infected tubers. In total, two isolates were obtained in 2007 and four isolates were collected in 2008. Five nitrate-nonutilizing mutants were generated, all of which were classified as VCG 4A. All six isolates collected from infected tubers used in this study were pathogenic on potato and AUSPC values were not significantly $(P \geq 0.05)$ different from isolate 653 . When data from both trials were combined, all six isolates caused significantly greater AUSPC values compared with the VCG 4B $(P \leq 0.0008)$ and water-inoculated $(P \leq 0.0003)$ controls (Table 2).

\section{Discussion}

The role of soilborne microsclerotia as primary inoculum of $V$. dahliae has long been recognized; however, the pathogen can also be found in the vascular tissue of certified seed tubers. Several field experiments have demonstrated that, despite the presence of Verticillium spp. in certified seed lots $(16,39,48)$, vascular infection of seed tubers has little effect on Verticillium wilt symptoms or potato yields in various potato cultivars. These studies used cultivars under limited current cultivation $(23,41)$, artificially inoculated tubers (47), or V. albo-atrum (42) and focused on the effects of tuber infection on aboveground symptoms, yield, quality, and vascular discoloration of progeny tubers. In addition, the potential contribution of seed tuber infection to the formation of future inoculum (i.e., microsclerotia) has not previously been quantified. In this study, intratuber infection exhibited a negligible effect on the development of Verticillium wilt symptoms in the widely grown but moderately susceptible potato Russet Burbank and premature senescence was observed only in plants grown in infested soil. AUSPC and senescence ratio values of plants grown in infested soil were similar regardless of intratuber infection, and additive or synergistic effects were not detected between soilborne and intratuber inoculum. Seed piece infection did not significantly contribute to aboveground stem colonization of the plant or the formation of microsclerotia in debris.

The results of this study are of practical importance because naturally infected tubers were used and the negligible effect of intratuber infection on premature senescence and disease severity was apparent in both trials. In addition, the amount of soilborne inoculum used $\left(10 \mathrm{CFU} / \mathrm{cm}^{3}\right.$ of soil) was relatively low, especially considering that the inoculum threshold of $V$. dahliae is generally considered to be at least $5 \mathrm{CFU} / \mathrm{g}$ of soil $(7,40)$ and levels of $V$. dahliae in fields can often be greater than $10 \mathrm{CFU} / \mathrm{g}$ of soil $(15,29,38)$. Artificially inoculated tubers were not used because artificial inoculation does not completely simulate the natural infection process and it is difficult to obtain a sufficient number of infected tubers for study.

Previous studies of $V$. dahliae isolates collected from potato plants and potato fields in Oregon and Washington found that the majority of isolates belong to VCG 4A and VCG 4B, with VCG 4A being highly aggressiveness on potato compared with other VCGs $(25,38,39)$. The six isolates obtained from infected tubers used in this study were highly aggressive on potato when plants were inoculated using a conidial soil drench, and five of these isolates were characterized as VCG 4A. Omer et al. (39) demonstrated that nearly two-thirds of infected seed tubers intended for commercial potato production contained isolates of the more aggressive VCG $4 \mathrm{~A}$ and approximately one-third contained VCG 4B. It is reasonable to assume that a roughly similar frequency of VCG distribution was present in seed tubers used in this study. In addition, genetic analyses using previously described microsatellites (2) indicate that a highly clonal population of $V$. dahliae exists in infected seed tubers collected from certified seed lots grown in Idaho and Montana between 2007 and 2010 (unpublished data).

The importance of soilborne inoculum in Verticillium wilt of potato, both for disease development and long-term survival of the pathogen, has been recognized for quite some time $(22,30,43,46)$. Furthermore, infested soil carried on the surface of seed tubers has also been shown to contribute to Verticillium wilt symptoms $(42,47)$. Nitzan et al. (36) suggested that the distribution of soilborne $C$. coccodes inoculum in the root zone provides more potential points of infection, which may also be true for $V$. dahliae. In addition to the potential for widespread distribution in the root zone, microsclerotia in soil are capable of repeated germination and can essentially function as several CFU over time, increasing the potential to cause infection and reducing the number of propagules required to cause disease (18).

Table 2. Mean area under senescence progress curve (AUSPC) values for 'Russet Burbank' potato plants inoculated with Verticillium dahliae

\begin{tabular}{lrc}
\hline & \multicolumn{2}{c}{ AUSPC $^{\mathbf{y}}$} \\
\cline { 2 - 3 } Isolate $^{\mathbf{z}}$ & Trial 1 & Trial 2 \\
\hline Water control & $486^{*}$ & $289^{*}$ \\
239 (VCG 4B) & $503^{*}$ & $363^{*}$ \\
653 (VCG 4A) & 1,234 & 1,873 \\
$2007-1$ & 897 & 1,654 \\
$2007-2$ & 893 & 1,540 \\
$2008-1$ & 1,050 & 1,698 \\
$2008-2$ & 761 & 1,618 \\
$2008-3$ & 1,299 & 1,593 \\
$2008-4$ & 1,234 & 1,435 \\
\hline
\end{tabular}

${ }^{y}$ Values with an asterisk $(*)$ indicate a significant $(P<0.05)$ difference with isolate 653 using Dunnett's procedure.

${ }^{\mathrm{z}}$ Six isolates were obtained from infected tubers used in this study and tested for aggressiveness on potato. Isolates 653 (VCG 4A control) and 239 (VCG 4B control), both obtained from potato, and a water control were also included.

Table 1. Mean area under senescence progress curve (AUSPC) values, senescence ratios, microsclerotia colonization, and incidence of progeny tuber infection in 'Russet Burbank' potato plants grown from Verticillium dahliae-infected and noninfected seed tubers in the presence and absence of soilborne inoculum ${ }^{2}$

\begin{tabular}{|c|c|c|c|c|c|c|c|c|c|}
\hline \multicolumn{2}{|c|}{ Inoculum sources } & \multicolumn{2}{|c|}{ AUSPC } & \multicolumn{2}{|c|}{ Senescence ratio } & \multicolumn{2}{|c|}{ Microsclerotia colonization $(\%)$} & \multicolumn{2}{|c|}{ Progeny tuber infection $(\%)$} \\
\hline Soil & Tuber & Trial 1 & Trial 2 & Trial 1 & Trial 2 & Trial 1 & Trial 2 & Trial 1 & Trial 2 \\
\hline None & None & $2,853 \mathrm{a}$ & $2,225 \mathrm{a}$ & $1.00 \mathrm{a}$ & $1.00 \mathrm{a}$ & $0.0 \mathrm{a}$ & $0.0 \mathrm{a}$ & $0.0 \mathrm{a}$ & $0.0 \mathrm{a}$ \\
\hline None & Infected & $3,273 \mathrm{a}$ & $2,347 \mathrm{a}$ & $1.15 \mathrm{a}$ & $1.05 \mathrm{a}$ & $0.6 \mathrm{a}$ & $0.3 \mathrm{a}$ & $0.0 \mathrm{a}$ & $0.0 \mathrm{a}$ \\
\hline Infested & None & $4,371 \mathrm{~b}$ & $3,151 \mathrm{~b}$ & $1.53 \mathrm{~b}$ & $1.42 \mathrm{~b}$ & $51.4 \mathrm{~b}$ & $45.3 \mathrm{~b}$ & $14.3 \mathrm{~b}$ & $25.7 \mathrm{~b}$ \\
\hline Infested & Infected & $4,367 \mathrm{~b}$ & $2,886 \mathrm{~b}$ & $1.53 \mathrm{~b}$ & $1.30 \mathrm{~b}$ & $46.3 \mathrm{~b}$ & $41.8 \mathrm{~b}$ & $13.7 \mathrm{~b}$ & $21.4 \mathrm{~b}$ \\
\hline
\end{tabular}

${ }^{\mathrm{z}}$ Treatment means compared with Tukey's honest significant difference; values with the same letter indicate no significant difference within the trial $(P>$ $0.05)$. 
Because vascular colonization is thought to be required for symptom development $(1,46,50)$ it is not completely understood why vascular infection by $V$. dahliae in potato seed tubers did not result in significant Verticillium wilt symptoms. Vascular colonization of aboveground stems was detected in only a few plants grown from infected tubers, indicating that the pathogen does not readily translocate from tuber vascular tissue to aboveground vascular tissue. Pathogen populations in the vascular system of the tuber may be below the threshold required to initiate colonization of the growing stems and cause disease. The pathogen may also be compartmentalized in progeny tubers during infection, storage, or growth, preventing complete colonization of the seed tuber and providing opportunities for sprouting eyes to escape infection. Previous studies on potato have shown varietal differences in the progression and density of vascular colonization by $V$. dahliae, with Verticillium wilt-resistant plants showing less vascular colonization than susceptible ones $(1,4,9)$.

Although potato plants grown from infected seed tubers did not exhibit significant Verticillium wilt symptoms during the current season, the possibility exists for $V$. dahliae to be introduced into a field by infected seed tubers and cause disease in subsequent crops. The movement of $V$. dahliae in infected seed tubers may also be important if the fungus or novel strains of the fungus become established in soils not previously used to grow potato, or where a management practice such as fumigation has been applied to reduce soilborne inoculum. Once established, propagules of $V$. dahliae from infected seed pieces could be moved within a field through plowing, irrigation, or other cultural practices and cause Verticillium wilt in the future.

The results of this study indicate that intratuber infection of seed tubers of Russet Burbank potato does not significantly contribute to premature senescence, progeny tuber infection, or inoculum production in aboveground plant debris; hence, management strategies should focus on soilborne inoculum. Because the use of soil fumigants is both costly and subject to future restrictions, other methods of reducing $V$. dahliae propagules in field soils need to be used. The use of partial or completely resistant cultivars, which can restrict vascular colonization and subsequent microsclerotia formation by $V$. dahliae, has the potential to both reduce symptoms and limit the amount of inoculum in field soils (10). Molecular detection methods, such as quantitative polymerase chain reaction, can be utilized to help develop resistant cultivars and monitor pathogen populations in the soil $(1,4)$. An integration of several control tactics, including host resistance (31), fumigation (21), green manures $(8,28)$, sanitation (11), irrigation management, (6) and other practices (26), will be necessary to sustainably manage potato production fields affected by Verticillium wilt in the future.

\section{Acknowledgments}

We thank the Washington State Potato Commission for financial support of this project and T. Cummings and J. Ingram for statistical, laboratory, and greenhouse assistance.

\section{Literature Cited}

1. Atallah, Z. K., Bae, J., Jansky, S. H., Rouse, D. I., and Stevenson, W. R. 2007. Multiplex real-time quantitative PCR to detect and quantify Verticillium dahliae colonization in potato lines that differ in response to Verticillium wilt. Phytopathology 97:865-872.

2. Atallah, Z. K., Maruthachalam, K., Davis, R. M., Klosterman, S. J., and Subbarao, K. V. 2009. Characterization of 22 highly polymorphic microsatellite loci in the cosmopolitan fungal plant pathogen Verticillium dahliae. Mol. Ecol. Res. 9:1460-1559.

3. Atibalentja, N., and Eastburn, D. M. 1997. Evaluation of inoculation methods for screening horseradish cultivars for resistance to Verticillium dahliae. Plant Dis. 81:356-362.

4. Bae, J., Atallah, Z. K., Jansky, S. H., Rouse, D. I., and Stevenson, W. R. 2007. Colonization dynamics and spatial progression of Verticillium dahliae in individual stems of two potato cultivars with differing responses to potato early dying. Plant Dis. 91:1137-1141.

5. Butterfield, E. J., and Devay, J. E. 1977. Reassessment of soil assays for Verticillium dahliae. Phytopathology 67:1073-1078.

6. Cappaert, M. R., Powelson, M. L., Christensen, N. W., and Crowe, F. J. 1992. Influence of irrigation on severity of potato early dying and tuber yield. Phytopathology 82:1448-1453.
7. Davis, J. R., and Everson, D. O. 1986. Relation of Verticillium dahliae in soil and potato tissue, irrigation method, and N-fertility to Verticillium wilt of potato. Phytopathology 76:730-736.

8. Davis, J. R., Huisman, O. C., Westermann, D. T., Hafez, S. L., Everson, D. O., Sorensen, L. H., and Schneider, A. T. 1996. Effects of green manures on Verticillium wilt of potato. Phytopathology 86:444-453.

9. Davis, J. R., Pavek, J. J., and Corsini, D. L. 1983. A sensitive method for quantifying Verticillium dahliae colonization in plant tissue and evaluating resistance among potato genotypes. Phytopathology 73:1009-1014.

10. Davis, J. R., Pavek, J. J., Corsini, D. L., Sorensen, L. H., Schneider, A. T. Everson, D. O., Westerman, D. T., and Huisman, O. C. 1994. Influence of continuous cropping of several potato clones on the epidemiology of Verticillium wilt of potato. Phytopathology 84:207-214.

11. Davis, J. R., Sorensen, L. H., Stark, J. C., and Westermann, D. T. 1990. Fertility and management practices to control Verticillium wilt of the Russet Burbank potato. Am. Potato J. 67:55-65.

12. Douhan, L. I., and Johnson, D. A. 2001. Vegetative compatibility and pathogenicity of Verticillium dahliae from spearmint and peppermint. Plant Dis. 85:297-302.

13. Dung, J. K. S., du Toit, L. J., and Johnson, D. A. 2011. Verticillium wilt of skullcap and potential for pathogen dissemination via seeds and stems. Plant Dis. 95:1147-1152.

14. Dunnett, C. W. 1955. A multiple comparisons procedure for comparing several treatments with a control. J. Am. Stat. Assoc. 509:1096-1121.

15. Easton, G. D. 1967. The number of Verticillium propagules in field soils in Washington. (Abstr.) Phytopathology 57:1004.

16. Easton, G. D., Nagle, M. E., and Bailey, D. L. 1972. Verticillium alboatrum carried by certified seed potatoes into Washington and control by chemicals. Am. Potato J. 49:397-402.

17. Ewing, E. 1981. Heat stress and the tuberization stimulus. Am. Potato J. 58:31-49.

18. Farley, J. D., Wilhelm, S., and Snyder, W. C. 1971. Repeated germination and sporulation of microsclerotia of Verticillium albo-atrum in soil. Phytopathology 61:260-264.

19. Fradin, E. F., and Thomma, B. P. H. J. 2006. Physiology and molecular aspects of Verticillium wilt diseases caused by V. dahliae and V. albo-atrum Mol. Plant Pathol. 7:71-86.

20. Francl, L. J., Madden, L. V., Rowe, R. C., and Riedel, R. M. 1990. Correlation of growing season environmental variables and the effect of early dying on potato yield. Phytopathology 80:425-432.

21. Gamliel, A., Grinstein, A., Peretz, Y., Klein, L., Nachmias, A., Tsror, N. L., Livescu, L., and Katan, J. 1997. Reduced dosage of methyl bromide for controlling Verticillium wilt of potato in experimental and commercia plots. Plant Dis. 81:469-474.

22. Green, R. J. 1969. Survival and inoculum potential of conidia and microsclerotia of Verticillium albo-atrum in soil. Phytopathology 59:874-876.

23. Hoyman, W. G. 1974. Consequence of planting Norgold Russet seed infected with Verticillium albo-atrum. Am. Potato J. 51:22-25.

24. Joaquim, T. R., and Rowe, R. C. 1990. Reassessment of vegetative compatibility relationships among strains of Verticillium dahliae using nitratenonutilizing mutants. Phytopathology 80:1160-1166.

25. Joaquim, T. R., and Rowe, R. C. 1991. Vegetative compatibility and virulence of strains of Verticillium dahliae from soil and potato plants. Phytopathology 81:552-558.

26. Johnson, D. A., and Dung, J. K. S. 2010. Verticillium wilt of potato-the pathogen, disease and management. Can. J. Plant Pathol. 32:58-67.

27. Johnson, K. B., Radcliffe, E. B., and Teng, P. S. 1986. Effects of interacting populations of Alternaria solani, Verticillium dahliae, and the potato leafhopper (Empoasca fabae) on potato yield. Phytopathology 76:1046-1052.

28. Larkin, R. P., Honeycutt, C. W., and Olanya, O. M. 2011. Management of Verticillium wilt of potato with disease-suppressive green manures and as affected by previous cropping history. Plant Dis. 95:568-576.

29. Martinson, C. A., and Horner, C. E. 1962. Importance of nonhosts in maintaining the inoculum potential of Verticillium. (Abstr.) Phytopathology $52: 742$

30. Menzies, J. D., and Griebel, G. E. 1967. Survival and saprophytic growth of Verticillium dahliae in uncropped soil. Phytopathology 57:703-709.

31. Mohan, S., Davis, J., Corsini, D., Sorensen, L., and Pavek, J. 1990. Reaction of potato clones and accessions of Solanum spp. to Verticillium dahliae Kleb. and its toxin. Potato Res. 33:449-458.

32. Mol, L. 1995. Effect of plant roots on the germination of microsclerotia of Verticillium dahliae. II. Quantitative analysis of the luring effect of crops. Eur. J. Plant Pathol. 101:679-685.

33. Mol, L., and Scholte, K. 1995. Formation of microsclerotia of Verticillium dahliae Kleb. on various plant parts of two potato cultivars. Potato Res. 38:143-150.

34. Nachmias, A., and Krikun, J. 1984. Transmission of Verticillium dahliae in potato tubers. Phytopathology 74:535-537.

35. National Agricultural Statistics Service. Crop Production. 2009. United States Department of Agriculture, Washington, DC

36. Nitzan, N., Cummings, T. F., and Johnson, D. A. 2008. Disease potential of soil- and tuberborne inocula of Colletotrichum coccodes and black dot severity on potato. Plant Dis. 92:1497-1502.

37. Nnodu, E., and Harrison, M. 1979. The relationship between Verticillium 
albo-atrum inoculum density and potato yield. Am. Potato J. 56:11-25.

38. Omer, M. A., Johnson, D. A., Douhan, L. I., Hamm, P. B., and Rowe, R. C. 2008. Detection, quantification, and vegetative compatibility of Verticillium dahliae in potato and mint production soils in the Columbia Basin of Oregon and Washington. Plant Dis. 92:1127-1131.

39. Omer, M. A., Johnson, D. A., and Rowe, R. C. 2000. Recovery of Verticillium dahliae from North American certified seed potatoes and characterization of strains by vegetative compatibility and aggressiveness. Am. J. Potato Res. 77:325-331.

40. Powelson, M. L., and Rowe, R. C. 1993. Biology and management of early dying of potatoes. Annu. Rev. Phytopathol. 31:111-126.

41. Robinson, D. B., and Ayers, G. W. 1953. The control of Verticillium wilt of potatoes by seed treatment. Can. J. Agric. Sci. 33:147-152.

42. Robinson, D. B., and Ayers, G. W. 1961. Verticillium wilt of potato in relation to vascular infection of the tuber. Can. J. Plant Sci. 41:703-708.

43. Rowe, R. C. 1985. Potato early dying - a serious threat to the potato industry. Am. Potato J. 62:157-161

44. Rowe, R. C., Davis, J. R., Powelson, M. L., and Rouse, D. I. 1987. Potato early dying: causal agents and management strategies. Plant Dis. 71:482-489.

45. Rowe, R. C., Riedel, R. M., and Martin, M. J. 1985. Synergistic interactions between Verticillium dahliae and Pratylenchus penetrans in potato early dying disease. Phytopathology 75:412-418.

46. Schnathorst, W. C. 1981. Life cycle and epidemiology of Verticillium. Pages 81-111 in: Fungal Wilt Diseases of Plants. M. E. Mace, A. A. Bell, and C. H. Beckman, eds. Academic Press, New York.

47. Thanassoulopoulos, C. C., and Hooker, W. J. 1968. Factors influencing infection of field grown potato by Verticillium albo-atrum. Am. Potato J. 45:203-216.

48. Tsror (Lahkim), L., Aharon, M., and Erlich, O. 1999. Survey of bacteria and fungal seedborne diseases in imported and domestic potato seed tubers. Phytoparasitica 27:215-226.

49. Tukey, J. W. 1949. Comparing individual means in the analysis of variance. Biometrics 5:99-114.

50. Vallad, G. E., and Subbarao, K. V. 2008. Colonization of resistant and susceptible lettuce cultivars by a green fluorescent protein-tagged isolate of Verticillium dahliae. Phytopathology 98:871-885.

51. Whitworth, J. L., and Davidson, R. D. 2008. Quality seed: Seed improvement, cultivar and seed lot selection, and certification. Pages 31-41 in: Potato Health Management. D. A. Johnson, ed. American Phytopathological Society, St. Paul, MN 